\title{
Plant Defensin Peptides have Antifungal and Antibacterial Activity Against Human and Plant Pathogens
}

\author{
Andrew E. Sathoff, ${ }^{1, \dagger}$ Siva Velivelli,2 Dilip M. Shah,2 and Deborah A. Samac',3 \\ ${ }^{1}$ Department of Plant Pathology, 1991 Upper Buford Circle, University of Minnesota, St. Paul, MN 55108; 2Donald Danforth Plant Science \\ Center, 975 North Warson Road, St. Louis, MO 63132; and ${ }^{3}$ United States Department of Agriculture-Agricultural Research Service, Plant \\ Science Research Unit, 1991 Upper Buford Circle, St. Paul, MN 55108. \\ Accepted for publication 19 September 2018.
}

\begin{abstract}
Plant defensins are small, cysteine-rich antimicrobial peptides. These peptides have previously been shown to primarily inhibit the growth of fungal plant pathogens. Plant defensins have a $\gamma$-core motif, defined as $\mathrm{GXCX}_{3-9} \mathrm{C}$, which is required for their antifungal activity. To evaluate plant defensins as a potential control for a problematic agricultural disease (alfalfa crown rot), short, chemically synthesized peptides containing $\gamma$-core motif sequences were screened for activity against numerous crown rot pathogens. These peptides showed both antifungal and, surprisingly, antibacterial activity. Core motif peptides from Medicago truncatula

defensins (MtDef4 and MtDef5) displayed high activity against both plant and human bacterial pathogens in vitro. Full-length defensins had higher antimicrobial activity compared with the peptides containing their predictive $\gamma$-core motifs. These results show the future promise for controlling a wide array of economically important fungal and bacterial plant pathogens through the transgenic expression of a plant defensin. They also suggest that plant defensins may be an untapped reservoir for development of therapeutic compounds for combating human and animal pathogens.
\end{abstract}

Peptides and small proteins with antimicrobial activity have been identified in a wide array of organisms (Dias and Franco 2015). Because they are found in vertebrates, invertebrates, plants, and fungi, they may constitute an ancient, conserved line of defense against pathogen invasion that predates the divergence in eukaryotes (Carvalho and Gomes 2009). Plant defensins are cysteine-rich, cationic antimicrobial peptides of 45 to 54 amino acid residues. These peptides have a highly conserved three-dimensional structure consisting of one $\alpha$-helix and three antiparallel $\beta$-strands that are connected by four disulfide bonds, forming a cysteine-stabilized $\alpha \beta$ $(\mathrm{CS} \alpha \beta)$ motif (De Coninck et al. 2013; Francisco and Georgina 2017; Lay and Anderson 2005; Vriens et al. 2014). The structure of each plant defensin has a functionally important $\gamma$-core motif, $\mathrm{GXCX}_{3-9} \mathrm{C}$, which alone can confer antimicrobial activity (Sagaram et al. 2011; Yount and Yeaman 2004). Despite their structural uniformity, plant defensins exhibit very low sequence similarity outside the eight distinctively conserved cysteines (Thomma et al. 2002; van der Weerden and Anderson 2013). This divergence in primary sequences may account for different biological functions attributed to plant defensins, including antifungal and antibacterial activity, pollen tube guidance, and roles in plant development (Carvalho and Gomes 2009).

Many plant defensins exhibit potent activity in vitro, inhibiting the growth of fungi and oomycetes at micromolar concentrations. However, they differ considerably in the spectrum of organisms inhibited and modes of action (MOA). The initial studies aimed at revealing MOA of plant defensins identified interactions with fungal-specific membrane components (Thevissen et al. 1997, $2000,2004)$. Defensins were shown to permeabilize fungal plasma membranes, induce $\mathrm{Ca}^{2+}$ influx, and disrupt a $\mathrm{Ca}^{2+}$ gradient essential for polar growth of hyphal tips (Thevissen et al. 1996, $1997,1999)$. Some defensins bind with high affinity to specific sphingolipids present in the fungal cell wall or plasma membrane of their target fungi (Aerts et al. 2008; Thevissen et al. 2005, 2007).

${ }^{\dagger}$ Corresponding author: Andrew Sathoff; E-mail: satho002@umn.edu

(c) 2019 The American Phytopathological Society
During the last few years, several antifungal plant defensins, including Psd1 from Pisum sativum, NaD1 from Nicotiana alata, TPP3 from Solanum lycopersicum, NsD7 from N. suaveolens, and MtDef4 and MtDef5 from Medicago truncatula, have been shown to gain entry into fungal cells and interact with bioactive plasma membrane resident phospholipids, cause membrane permeabilization, and induce fungal cell death (Aerts et al. 2008; Lobo et al. 2007; Parisi et al. in press; Thevissen et al. 2004). It has been proposed that these peptides have multiple targets in fungal cells. Thus, in addition to disrupting the plasma membrane, these peptides likely bind to intracellular targets, induce production of reactive oxygen species, and inhibit cell division.

Although several plant defensins have been extensively studied for their antifungal activity, fewer defensins with antibacterial activity have been reported (van der Weerden and Anderson 2013). For example, Cp-thionin II from cowpea (Franco et al. 2006), DmAMP1 from Dahlia merckii, CtAMP1 from Clitoria ternatea, AhAMP1 from Aesculus hippocastanum (Osborn et al. 1995), ZmESR-6 from maize (Balandín et al. 2005), fabatin from broad been (Zhang and Lewis 1997), and SOD2 and SOD7 from spinach (Segura et al. 1998) have been reported to exhibit antibacterial activity against a range of Gram-positive and Gram-negative bacterial pathogens. Among antibacterial defensins, SOD2 and SOD7 from spinach have been demonstrated to confer resistance to Asiatic citrus canker and huanglongbing caused by Xanthomonas citri subsp. citri and 'Candidatus Liberibacter' spp., respectively, in transgenic citrus (Stover et al. 2013). The MOA of antibacterial plant defensins have yet to be deciphered in detail.

Alfalfa ( $M$. sativa), a perennial plant in the legume family, is among the most valuable crops in the United States, with a direct value of over $\$ 8$ billion annually. Alfalfa production is essential for sustaining the dairy industry, which used an estimated 14 million tons of alfalfa in 2016. Plant pathogens and nematodes that infect alfalfa account for an estimated $\$ 400$ million in economic losses annually (Leath et al. 1988). Crown rot, caused by a complex of soil microbes, is one of the most important alfalfa diseases across the United States. The organisms causing crown rot can differ substantially by geographic location. Some of the most common pathogenic fungal species are Phoma medicaginis, Rhizoctonia 
solani, Fusarium oxysporum, F. roseum, and F. solani (Turner and Van Alfen 1983; Uddin and Knous 1991; Wilcoxson et al. 1977). Bacteria (Clavibacter insidiosus and Pseudomonas spp.) and oomycetes (Pythium spp.) are also associated with the disease complex. Another economically important alfalfa disease, Aphanomyces root rot caused by Aphanomyces euteiches, often accompanies crown rot in soil with poor drainage. Crown rot occurs to some extent in every alfalfa stand that is over 1 year old and is the major source of stand decline and yield loss.

Breeding for resistance has been successfully employed to manage several alfalfa diseases but resistance has not been identified for developing crown rot resistant cultivars. Fungicides with the required persistent root and crown activity are not available. Lack of cultural and chemical management practices for this disease severely limits alfalfa production. Thus, there is an immediate need for development of innovative methods to manage crown rot for enhanced alfalfa persistence and yields.

We have recently reported the antibacterial activity of a bidomain defensin, MtDef5, from M. truncatula, a model plant species closely related to alfalfa, against the Gram-negative bacterial pathogen $X$. campestris. MtDef5 permeabilizes the plasma membrane and translocates into the cells of this bacterial pathogen. In vitro, it also binds to DNA (Velivelli et al. 2018). In this study, we identified plant defensin peptides that inhibit the in vitro growth of alfalfa crown rot pathogens. We also discovered that they inhibit the growth of several human bacterial pathogens. Synthetic $\gamma$-core motifs were used to initially screen for activity against numerous fungal and bacterial pathogens. The $\gamma$-core motifs from M. truncatula had the greatest antagonistic biological activity against the evaluated pathogens. However, the corresponding fulllength defensins displayed enhanced activity compared with the $\gamma$-core motifs. These results not only indicate that transgenic expression of plant defensins in alfalfa has the potential to provide improved resistance to crown rot disease in alfalfa but also that plant defensins and short peptides derived from them may be a valuable resource for the development of therapeutic compounds with novel modes of action to combat human pathogens.

\section{MATERIALS AND METHODS}

Pathogen cultures and growth media. All fungal pathogen strains were isolated from infected alfalfa plants collected in Minnesota from commercial production fields and deposited in the University of Minnesota Mycological Culture Collection. The fungal strains $F$. oxysporum f. sp. medicaginis $7 \mathrm{~F}-3, F$. oxysporum f. sp. medicaginis $31 \mathrm{~F}-3, F$. solani, F. tricinctum, F. incarnatum, F. redolens, Colletotrichum trifolii WS-5, C. trifolii FG-1, P. medicaginis STC, and $P$. medicaginis WS-2 were grown on potato dextrose agar (Difco, Sparks, MD) at $25^{\circ} \mathrm{C}$. After 1 to 2 weeks of culture growth, conidia were harvested by washing the plates with sterile water. The spore suspensions were filtered and spore densities were determined microscopically using a hemocytometer.

A. euteiches MF-1 (race 1) and A. euteiches MER4 (race 2) were grown on corn meal agar (Difco) at $25^{\circ} \mathrm{C}$ for 1 week. Agar disks ( $7 \mathrm{~mm}$ in diameter) from the margin of the A. euteiches colonized medium were cultured in liquid peptone glucose (PG) medium containing peptone at $20 \mathrm{~g} / \mathrm{liter}$ and glucose at $5 \mathrm{~g} / \mathrm{liter}$ at $20^{\circ} \mathrm{C}$ for $24 \mathrm{~h}$. To trigger zoospore production, PG medium was removed and agar disks were washed with sterile spring water at $0,1,2,4$, and $6 \mathrm{~h}$ after PG media removal by resuspending in $100 \mathrm{ml}$ of sterile spring water. The final resuspension had just enough volume to immerse the disks in approximately $15 \mathrm{ml}$ of sterile spring water. Zoospores were harvested $18 \mathrm{~h}$ after the final resuspension. Spore densities were determined microscopically using a hemocytometer.

From glycerol stocks, the bacterial strains Pseudomonas syringae pv. syringae ALF3, X. alfalfae subsp. alfalfae F3, Escherichia coli DH5 $\alpha$, Sinorhizobium meliloti 102F51, Clavibacter insidiosus R13 , and $C$. insidiosus R1-1 were cultured on nutrient broth yeast extract (NBY) agar at $30^{\circ} \mathrm{C}$. After 2 days of growth, the bacterial cells were harvested by flooding the plates with sterile water. The American Type Culture Collection reference strains of human pathogenic bacteria $P$. aeruginosa PAO1, Serratia marcescens, Enterobacter aerogenes, and Enterococcus casseliflavus were obtained from Dr. Foster-Hartnett at the University of Minnesota and were cultured on Luria-Bertani (LB) agar (Difco) at $37^{\circ} \mathrm{C}$. After 1 day of growth, the bacterial cells were harvested by flooding the plates with sterile water.

Defensin peptide synthesis. The $\gamma$-core motif peptides derived from plant defensins MsDef1, MtDef4, MtDef5, RsAFP2, and So-D2 (Gao et al. 2000; Islam et al. 2017; Sagaram et al. 2011; Segura et al. 1998; Terras et al. 1992) (Table 1) were chemically synthesized and purified by high-performance liquid chromatography (LifeTein, Somerset, NJ).

Full-length clones encoding MtDef4 and MtDef5 were expressed in Pichia pastoris, and the peptides were purified as previously described (Islam et al. 2017; Spelbrink et al. 2004). Defensins were lyophilized and resuspended in nuclease-free water. The concentration of each defensin was determined by NanoDrop spectrophotometry. Approximately $3 \mathrm{mg}$ of purified protein was collected from 1 liter of $P$. pastoris culture expressing the defensin.

In vitro defensin antifungal activity determination. A microplate reader assay adapted from Broekaert et al. (1990) using absorption as a measure for fungal growth was utilized to monitor growth inhibition by the $\gamma$-core motif peptides and fulllength defensins. Flat, clear-bottom, 96-well microplates (Corning, Corning, NY) were used with each well containing half-strength potato dextrose broth (Difco), approximately 2,000 spores, and a defensin peptide at concentrations of $0,5,10,15$, or $30 \mu \mathrm{g} / \mathrm{ml}$ in a total volume of $100 \mu \mathrm{l}$. Samples were assayed in triplicate. The microplates were shaken on an orbital shaker and spores were allowed to sediment for $30 \mathrm{~min}$ before absorbance was measured. The absorbance of the wells was measured at $595 \mathrm{~nm}$ on a Synergy H1 microplate reader (BioTek, Winooski, VT). Further absorbance measurements were carried out after 24- and 48-h incubation periods at $25^{\circ} \mathrm{C}$. To quantify fungal growth, the initial absorbance measurement was subtracted from the final absorbance measurement at $48 \mathrm{~h}$. The changes in absorbance were averaged across the three replications and a dose-response curve was created by performing a regression using Microsoft Excel 2016. The amount of defensin needed to inhibit growth of the fungal pathogens strains by $50 \%\left(\mathrm{IC}_{50}\right)$ was calculated from dose response curves as previously described (Terras et al. 1992). This assay was repeated three times for each fungal pathogen. The $\mathrm{IC}_{50}$ values are presented as mean \pm standard error from the three experiments.

Antibacterial activity screen. Cell suspensions were diluted with sterile water to an optical density at $600 \mathrm{~nm}\left(\mathrm{OD}_{600}\right)$ of 0.1 . Plates of NBY were spread with $100 \mu \mathrm{l}$ of bacteria to create a bacterial lawn. The plates were dried for $10 \mathrm{~min}$ before placing sterile filter paper disks containing $30,10,5$, or $0 \mu \mathrm{g}$ of defensin peptide onto plates. Each bacterial lawn had 12 filter paper disks ( 3 disks of each defensin concentration), and this experiment was repeated three times on separate NBY plates. The bacterial plates were incubated for 1 or 2 days at $25^{\circ} \mathrm{C}$. If zones of bacterial growth inhibition were observed, the defensin was considered to have antibacterial activity. The diameter of zones of inhibition was

TABLE 1. Amino acid sequences of $\gamma$-core motif (bold) and C-terminal region (italics) of plant defensins tested in vitro

\begin{tabular}{ll}
\hline Defensin & \multicolumn{1}{c}{ Amino acid sequence } \\
\hline MsDef1 & GRCRDDFRCWCTKRC \\
MtDef4 & GRCRGFRRRC $F C T H C$ \\
MtDef5 & GACHRQGFGFAC $F C$ H $K C$ \\
RsAFP-2 & GSCNYVFPAHKCICYFP \\
So-D2 & GDCKGIRRRC $M C S K P L$ \\
\hline
\end{tabular}


measured, and the average area of the zones of inhibition was determined using the formula area $=\pi r^{2}$.

In vitro defensin antibacterial activity determination. To quantify antibacterial activity, a spread-plate assay was used for both full-length defensins and $\gamma$-core defensin peptides and was repeated three times for each bacterial pathogen. As was done in our initial antibacterial screen, bacterial lawns of Pseudomonas syringae pv. syringae and X. alfalfae subsp. alfalfae were grown on NBY plates for 2 days. The human pathogens $S$. marcescens, Enterobacter aerogenes, and $P$. aeruginosa were grown on LB plates for 1 day. The alfalfa bacterial wilt pathogen $C$. insidiosus was grown on NBY for 1 week. The plates were flooded with sterile water, and bacteria were harvested by rubbing with a sterile rubber policeman. Cultures were diluted with sterile water to an $\mathrm{OD}_{600}$ of 0.1 . In microcentrifuge tubes, $200 \mu \mathrm{l}$ of bacteria was incubated at $30^{\circ} \mathrm{C}$ with shaking for $3 \mathrm{~h}$ with various concentrations of a defensin peptide $(0,2.5,5,10,15$, or $30 \mu \mathrm{g} / \mathrm{ml})$. After the peptide treatment, 10 -fold serial dilutions were made, and $100 \mu \mathrm{l}$ were plated in triplicate onto NBY plates. CFU were counted for $P$. syringae pv. syringae and $X$. alfalfae subsp. alfalfae after incubation for 2 days at $30^{\circ} \mathrm{C}$; for $S$. marcescens, E. aerogenes, Enterococcus casseliflavus, and $P$. aeruginosa incubated 1 day at $37^{\circ} \mathrm{C}$; and for $C$. insidiosus incubated for 7 days at $25^{\circ} \mathrm{C}$. Regression of the average $\mathrm{CFU}$ were across experimental replications, whereas the defensin concentration was used to create a dose-response curve using Microsoft Excel 2016. From these curves, the $\mathrm{IC}_{50}$ was calculated. The $\mathrm{IC}_{50}$ values are presented as mean \pm standard error from three experiments.

\section{RESULTS}

Antifungal activity. The $\gamma$-core motif peptides derived from MsDef1, MtDef4, MtDef5, RsAFP-2, and So-D2 (Table 1) demonstrated antifungal activity at micromolar concentrations (Table 2). Overall, the $\gamma$-core motif of MtDef4 exhibited a wider spectrum of antifungal activity than the corresponding motif from other defensins tested. In particular, MtDef4 inhibited the growth of $P$. medicaginis and F. solani, with $\mathrm{IC}_{50}$ values of 5.3 to 7.3 and $6.0 \mu \mathrm{M}$, respectively. This peptide inhibited spore germination as well as germ tube elongation and mycelial growth of both fungi but did not result in morphological changes of spores or hyphae (Fig. 1). The $\gamma$-core motif of MtDef5 also inhibited the growth of $P$. medicaginis but had enhanced inhibition of $F$. solani, with an $\mathrm{IC}_{50}$ value of $4.1 \mu \mathrm{M}$, compared with the core motif of MtDef4. None of the $\gamma$-core motif peptides demonstrated activity against the oomycete pathogen A. euteiches, the fungal pathogen Colletotrichum trifolii, or, surprisingly, either $F$. redolens or $F$. incarnatum.

Because the $\gamma$-core motifs of MtDef4 and MtDef5 showed the greatest antifungal activity against alfalfa crown rot fungal pathogens, the corresponding full-length defensin peptides were evaluated for activity. Full-length MtDef4 and MtDef5 had greater inhibitory activity than their corresponding $\gamma$-core peptides against $P$. medicaginis and $F$. oxysporum f. sp. medicaginis, with $\mathrm{IC}_{50}$ values as low as 300 and $700 \mathrm{nM}$, respectively. The full-length defensins also caused inhibition of spore germination and mycelial growth (Fig. 2). Like the $\gamma$-core motifs, the full-length defensins also failed to inhibit the growth of A. euteiches and C. trifolii (Table 2). These results indicate that the $\gamma$-core motif peptides may be used to predict the relative antifungal activity of the corresponding full-length defensins, though additional comparisons need to be performed to see if this trend holds for other defensins.

Antibacterial activity. Considering that plant defensins rarely display antibacterial activity, a somewhat qualitative screen for biological activity was first utilized. The $\gamma$-core defensin peptides were initially screened for antibacterial activity on a bacterial lawn by measuring zones of inhibition resulting from defensin peptides spotted onto filter paper disks. The $\gamma$-core defensin peptides inhibited the growth of Escherichia coli, . syringae pv. syringae,
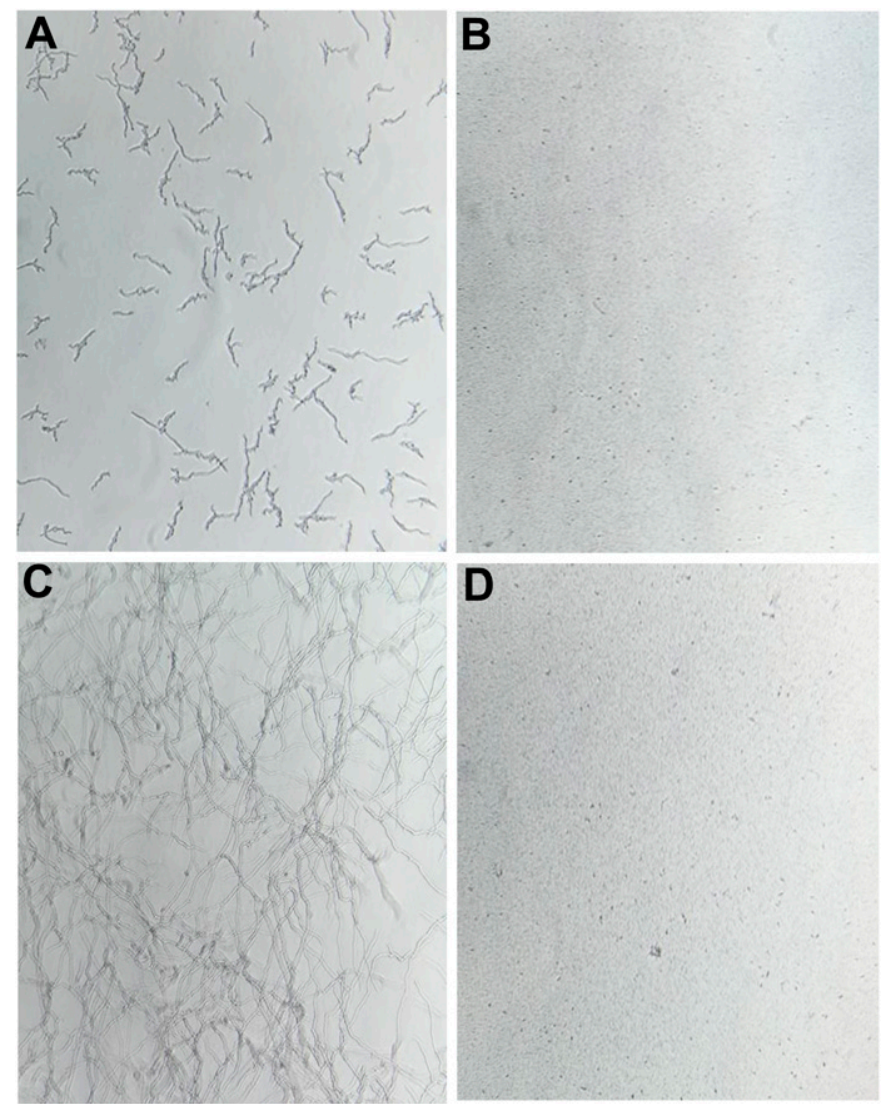

Fig. 1. The $\gamma$-core motif peptide from MtDef4 inhibited growth of alfalfa fungal crown rot pathogens in vitro. Spores of Phoma medicaginis were grown for $24 \mathrm{~h}$ at $25^{\circ} \mathrm{C}$ in potato dextrose broth (PDB) culture medium in $\mathbf{A}$, the absence or B, presence of $\gamma$-core MtDef4 at $30 \mu \mathrm{g} / \mathrm{ml}$. Spores of Fusarium oxysporum f. sp. medicaginis were grown for $24 \mathrm{~h}$ at $25^{\circ} \mathrm{C}$ in PDB culture medium in $\mathbf{C}$, the absence or $\mathbf{D}$, presence of $\gamma$-core MtDef4 at $30 \mu \mathrm{g} / \mathrm{ml}$.

TABLE 2. Activity of the $\gamma$-core motif defensin peptide constructs and full-length defensin peptides against fungal and oomycete alfalfa crown rot pathogens ${ }^{\text {a }}$

\begin{tabular}{|c|c|c|c|c|c|c|c|c|c|c|c|c|}
\hline \multirow[b]{2}{*}{ Defensin } & \multicolumn{2}{|c|}{$\begin{array}{l}\text { Fusarium oxysporum } \\
\text { f. sp. medicaginis }\end{array}$} & \multicolumn{2}{|c|}{ Phoma medicaginis } & \multicolumn{2}{|c|}{ Colletotrichum trifolii } & \multicolumn{2}{|c|}{$\begin{array}{l}\text { Aphanomyces } \\
\text { euteiches }\end{array}$} & \multirow[b]{2}{*}{ F. solani } & \multirow[b]{2}{*}{ F. tricinctum } & \multirow[b]{2}{*}{ F. redolens } & \multirow[b]{2}{*}{ F. incarnatum } \\
\hline & $7 F-3$ & $31 \mathrm{~F}-3$ & STC & WS-2 & FG-1 & WS-5 & Race 1 & Race 2 & & & & \\
\hline Core MsDef1 & NA & NA & $12.7 \pm 1.1$ & $14.8 \pm 1.0$ & NA & NA & NA & NA & NA & NA & NA & NA \\
\hline Core MtDef4 & $7.1 \pm 0.8$ & $6.9 \pm 0.8$ & $7.3 \pm 0.7$ & $5.3 \pm 0.7$ & NA & NA & NA & NA & $6.0 \pm 1.0$ & $14.7 \pm 1.3$ & NA & NA \\
\hline Core MtDef5 & NA & NA & $19.5 \pm 1.2$ & $8.5 \pm 1.0$ & NA & NA & NA & NA & $4.1 \pm 0.5$ & NA & NA & NA \\
\hline Core RsAFP2 & NA & NA & NA & NA & NA & NA & NA & NA & NA & $5.3 \pm 0.5$ & NA & NA \\
\hline Core So-D2 & $33.1 \pm 1.9$ & NA & $6.4 \pm 0.6$ & $6.1 \pm 0.6$ & NA & NA & NA & NA & $13.8 \pm 0.9$ & NA & NA & NA \\
\hline MtDef4 & $0.7 \pm 0.1$ & $1.9 \pm 0.1$ & $0.3 \pm 0.1$ & $2.6 \pm 0.1$ & NA & NA & NA & NA & ND & ND & ND & ND \\
\hline MtDef5 & $0.8 \pm 0.1$ & $1.3 \pm 0.1$ & $1.5 \pm 0.1$ & $1.6 \pm 0.1$ & NA & NA & NA & NA & ND & ND & ND & ND \\
\hline
\end{tabular}

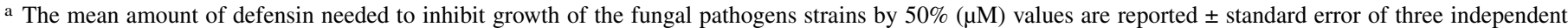
experiments $(n=3)$. NA indicates that the defensins at a concentration of $30 \mu \mathrm{g} / \mathrm{ml}$ showed no biological activity against the pathogens and ND indicates no data. 
Sinorhizobium meliloti, or X. alfalfae subsp. alfalfae to varying degrees (Fig. 3). The $\gamma$-core peptide from MtDef4 displayed the greatest antibacterial activity of the $\gamma$-core motif peptides tested. However, neither MtDef4 nor MtDef5 $\gamma$-core motifs inhibited the growth of the beneficial, nitrogen-fixing microsymbiont $S$. meliloti. Overall, the $\gamma$-core peptides displayed the greatest growth inhibition against $E$. coli using the filter paper disk assay.

Using a more quantitative spread-plate assay, the antibacterial activity of the $\gamma$-core motifs from MsDef1, MtDef4, MtDef5, and So-D2 against the bacterial plant pathogens were evaluated and found to exhibit antibacterial activity at micromolar concentrations. The MtDef4 and MtDef5 $\gamma$-core motifs inhibited the growth of $P$. syringae pv. syringae with $\mathrm{IC}_{50}$ values of 3.4 and $4.5 \mu \mathrm{M}$, respectively (Table 3 ). Notably, the MtDef4 $\gamma$-core motif peptide but not the MtDef5 $\gamma$-core peptide displayed antibacterial activity against $X$. alfalfae subsp. alfalfae.

The full-length defensins MtDef4 and MtDef5 were also characterized for antibacterial activity using the spread-plate method. In addition to the previously tested Gram-negative bacteria, antibacterial activity against a Gram-positive alfalfa bacterial wilt bacterium, Clavibacter insidiosus, was evaluated. The antibacterial activity of full-length MtDef4 and MtDef5 was enhanced as compared with their corresponding $\gamma$-core motifs. MtDef 4 and MtDef5 had $\mathrm{IC}_{50}$ values at nanomolar concentrations. In accordance with the $\gamma$-core motif results, MtDef4 and MtDef5 exhibited high activity against $P$. syringae pv. syringae, with $\mathrm{IC}_{50}$ values of 400 and $100 \mathrm{nM}$, respectively (Table 3). MtDef4 was most active against C. insidiosus, with an $\mathrm{IC}_{50}$ value of $100 \mathrm{nM}$. Again, MtDef5 displayed no antibacterial activity against $X$. alfalfae subsp. alfalfae, which further supports the predictive capacity of the $\gamma$-core motif peptides. The broad antibacterial activity of MtDef4 and MtDef5 against plant bacterial pathogens led us to conduct antibacterial tests against human pathogens using the spread-plate assay. MtDef4 and MtDef5 $\gamma$-core peptides displayed low $\mathrm{IC}_{50}$ values against the majority of human bacterial pathogens tested, with Enterobacter aerogenes being the most sensitive to both MtDef4 and MtDef5 (Table 4). No antibacterial activity was seen against the Grampositive bacterium Enterococcus casseliflavus.

\section{DISCUSSION}

Plant defensins are well known to have activity against plant fungal pathogens, inhibiting in vitro growth as well as reducing damage from fungal diseases when expressed in heterologous plant hosts. We tested plant defensin peptides against diverse pathogens and found that they displayed broad inhibitory activity against plant fungal pathogens causing alfalfa crown rot disease along with, remarkably, both human and plant bacterial pathogens. In addition to displaying extensive antifungal activity, MtDef4 had strong and broad-spectrum antibacterial activity with nanomolar $\mathrm{IC}_{50}$ values against both Gram-positive and Gram-negative bacteria (Table 3). There are few reports that cite antibacterial activity of plant defensins because, traditionally, they have been regarded to possess solely antifungal activity (Fujimura et al. 2003; Guillén-Chable et al. 2017; Segura et al. 1998; Velivelli et al. 2018). Spinach defensin (So-D2) displayed high activity against both Clavibacter michiganensis subsp. sepedonicus and Ralstonia solanacearum, which correspond to Gram-positive and Gram-negative bacteria, but So-D2 displayed limited activity against fungal pathogens (Segura et al. 1998). MtDef4, MtDef5, and MsDef1 are noteworthy defensins because they exhibit potency against Gram-positive, Gram-negative, and fungal pathogens. Our report demonstrates that extensively studied plant defensins can have high antibacterial activity against human and plant pathogens, which was previously overlooked. This suggests that other well-characterized plant defensins should be retested for antibacterial activity.

Of the fungi tested, none of the plant defensins inhibited Colletotrichum trifolii, F. redolens, or F. incarnatum (Table 2).
Defensin antimicrobial specificity is commonly observed. For example, RsAFP2 demonstrated extensive antifungal activity but displayed no activity against either Sclerotinia sclerotiorum or Rhizoctonia solani (Terras et al. 1992). This pathogen specificity could occur due to diverse modes of action, resulting from the rich diversity of the primary amino acid sequences of plant defensins. RsAFP-1 and RsAFP-2 differ from each other by only 2 amino acids in the primary structure but exhibit a striking difference in their antimicrobial activity (Terras et al. 1992). The antifungal modes of action of MsDef1, MtDef4, MtDef5, and RsAFP-2 all differ but their molecular modes of action all involve interactions with fungal membrane components (Cools et al. 2017; Islam et al. 2017; Parisi et al. in press). These resistant fungal pathogens could have structural differences in their membranes that inhibit defensin recognition.

The $M$. truncatula defensins that we tested against alfalfa crown rot pathogens and human bacterial pathogens are among the wellcharacterized plant defensins and have potent activity against other plant pathogens (Muñoz et al. 2014; Sagaram et al. 2011, 2013). When expressed in Arabidopsis and tomato, they give strong protection against virulent fungal pathogens and protect the plants from disease (Abdallah et al. 2010; Kaur et al. 2012; Sharma et al. 2017). However, the broad antibacterial activity of these defensins had not been previously characterized. In contrast to the antifungal modes of action, there is no proposed antibacterial mode of action for any plant defensin. Both the full-length MtDef5 and its $\gamma$-core motif failed to inhibit the growth of $X$. alfalfae subsp. alfalfae (Table 3), which was surprising because MtDef5 was previously shown to be active against $X$. campestris (Velivelli et al. 2018). The resistance of $X$. alfalfae subsp. alfalfae to MtDef5 may be due to the presence of a homolog of MtDef5 in alfalfa (Scc4a34_1890, 78.8\%

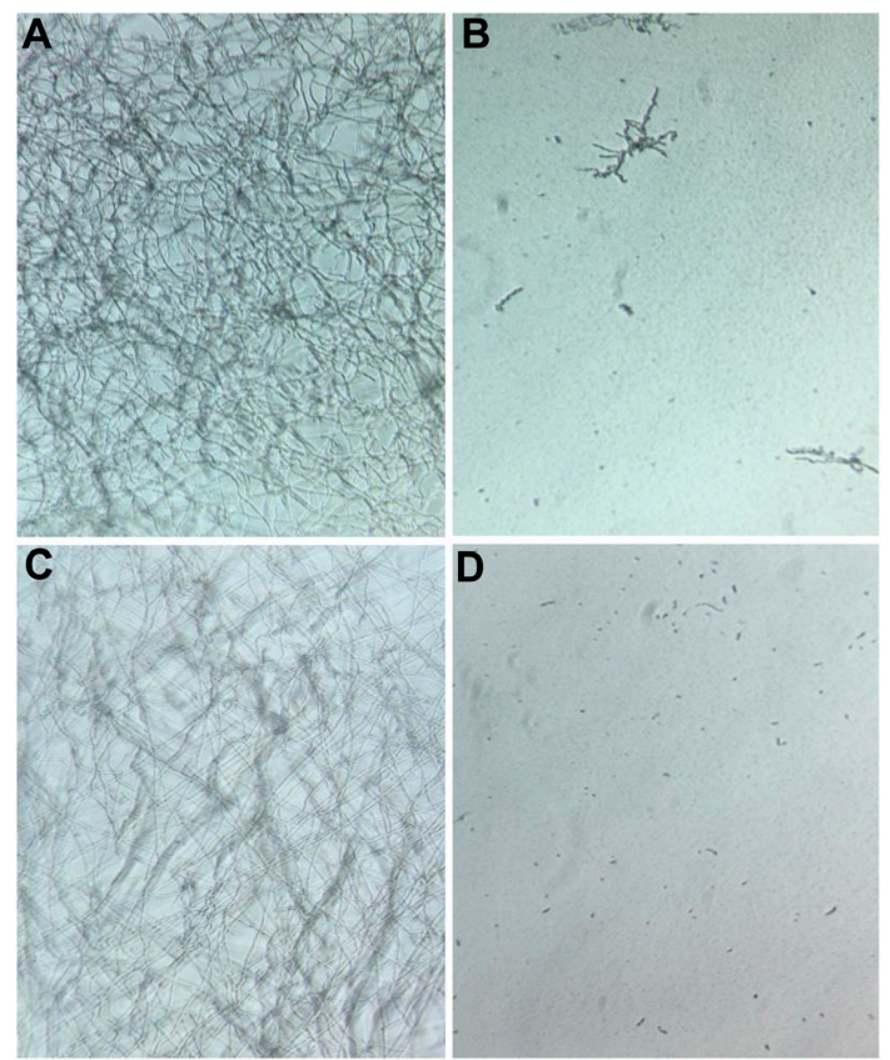

Fig. 2. Full-length MtDef4 inhibited growth of alfalfa fungal crown rot pathogens in vitro. Spores of Phoma medicaginis were grown for $48 \mathrm{~h}$ at $25^{\circ} \mathrm{C}$ in potato dextrose broth (PDB) culture medium in $\mathbf{A}$, the absence or $\mathbf{B}$, presence of full-length MtDef4 at $30 \mu \mathrm{g} / \mathrm{ml}$. Spores of Fusarium oxysporum $\mathrm{f}$. sp. medicaginis were grown for $48 \mathrm{~h}$ at $25^{\circ} \mathrm{C}$ in $\mathrm{PDB}$ culture medium in $\mathbf{C}$, the absence or D, presence of full-length MtDef4 at $30 \mu \mathrm{g} / \mathrm{ml}$. 
sequence identity). X. alfalfae subsp. alfalfae, a common alfalfa pathogen, could have become resistant to the MtDef5 homolog in alfalfa. Therefore, $X$. alfalfae subsp. alfalfae would be considered an adapted pathogen that has overcome the antibacterial activity of MtDef5. Plant defensins may be an excellent source for antibiotic development because human bacterial pathogens would be considered nonadapted to plant-derived defensins.

Currently, there are limited control and management strategies for the alfalfa crown rot disease complex. Alfalfa crown rot is ubiquitous and leads to stand decline, which leads to financial losses for the growers. This disease complex poses a complex problem. Pathogens gain entry into the crown through cut stems and mechanical damage to the root and crown that occur during the multiple foliage harvests throughout the year. Chemical control does not have the necessary persistence because pathogens decay the crowns during a period of months or years, predisposing them to winterkill and eventually killing the plant. Breeding efforts to increase quantitative resistance have made only minor progress (Miller-Garvin and Viands 1994). This report establishes plant defensins as potential agents for enhancing resistance to alfalfa crown rot, and possibly other diseases, through genetic modification.

Obtaining functional defensin peptides through heterologous expression can be a fastidious process. Amino acid substitutions, improper folding, and incorrect disulfide bridge formation all inhibit the biological activity of plant defensins (Vriens et al. 2014). Eukaryotic expression systems such as the often-utilized Pichia pastoris expression system can create constructs with the proper structure, disulfide bonds, and posttranslational modifications but the experimental setup can be difficult. Specialized Escherichia coli-based bacterial expression systems can generate copious

TABLE 3. Activity of the $\gamma$-core motif defensin peptides and full-length defensin peptides against bacterial alfalfa crown rot pathogens ${ }^{\mathrm{a}}$

\begin{tabular}{lccc}
\hline Defensin & $\begin{array}{c}\text { Xanthomonas alfalfae } \\
\text { subsp. alfalfae }\end{array}$ & $\begin{array}{c}\text { Pseudomonas } \\
\text { syringae } \mathrm{pv} \\
\text { syringae }\end{array}$ & $\begin{array}{c}\text { Clavibacter } \\
\text { insidiosus }\end{array}$ \\
\hline Core MtDef4 & $11.4 \pm 0.2$ & $3.4 \pm 0.4$ & ND \\
Core MtDef5 & NA & $4.5 \pm 0.5$ & ND \\
Core So-D2 & $19.3 \pm 2.2$ & $25.9 \pm 1.2$ & ND \\
Core MsDef1 & $7.9 \pm 0.7$ & $8.8 \pm 1.1$ & ND \\
MtDef4 & $0.6 \pm 0.04$ & $0.4 \pm 0.05$ & $0.1 \pm 0.01$ \\
MtDef5 & NA & $0.1 \pm 0.01$ & NA \\
\hline
\end{tabular}

a The mean amount of defensin needed to inhibit growth of the bacterial pathogens strains by $50 \%(\mu \mathrm{M})$ values are reported \pm standard error of three independent experiments $(n=3)$. NA indicates that the defensins at a concentration of $30 \mu \mathrm{g} / \mathrm{ml}$ showed no biological activity against the pathogens and ND indicates no data.
A

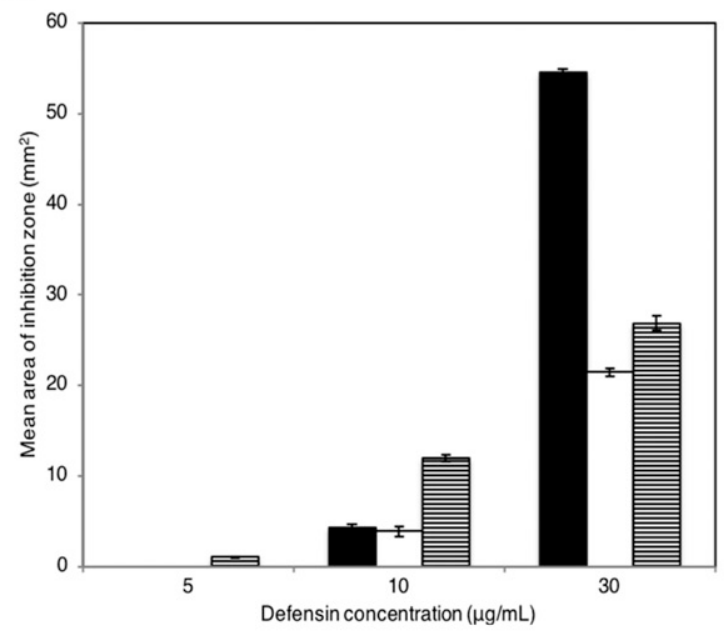

C

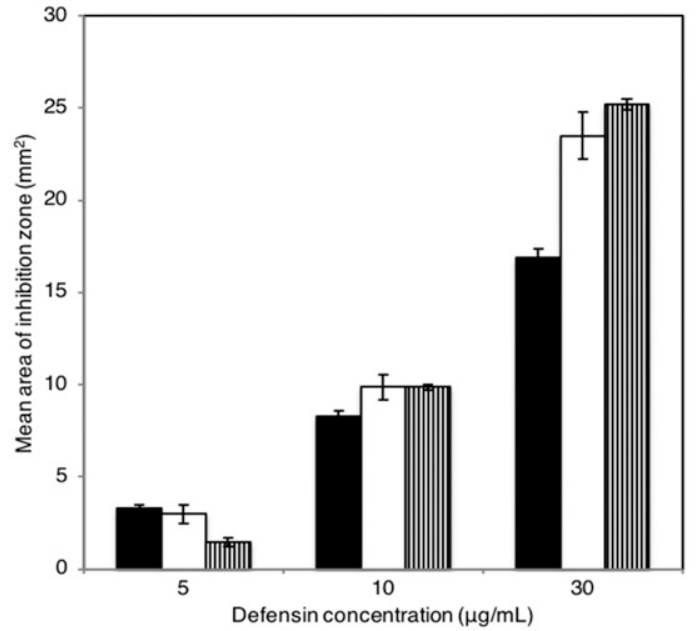

B

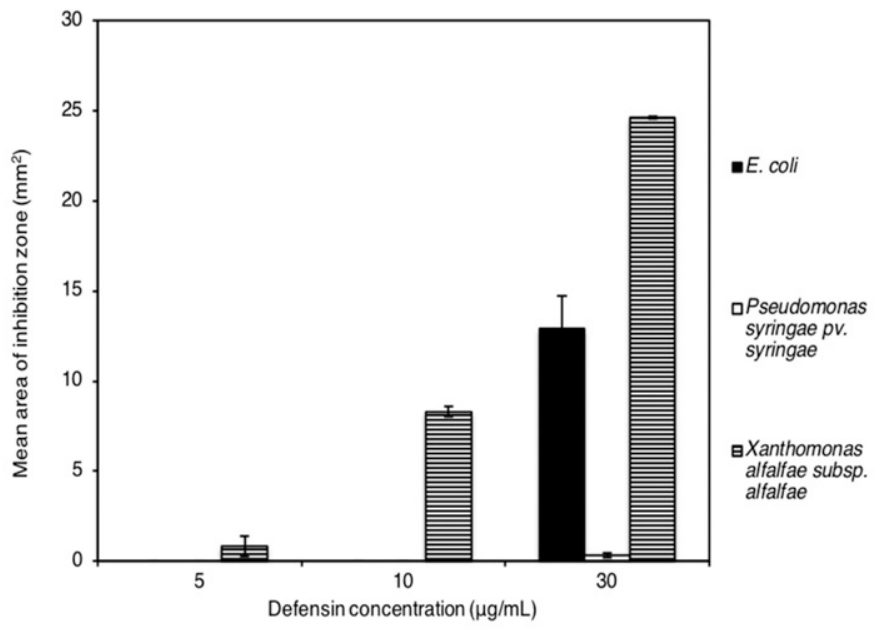

D

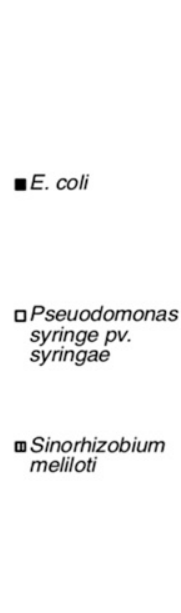

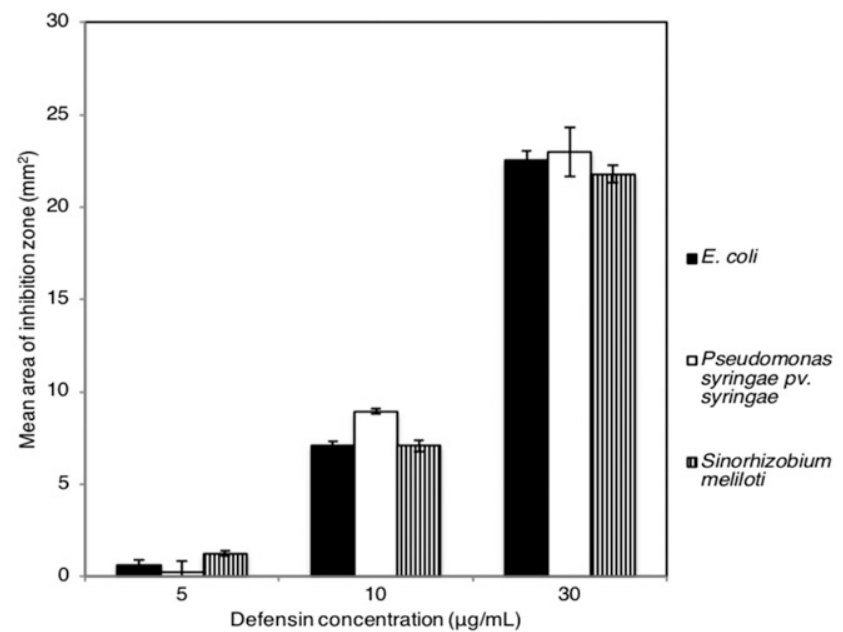

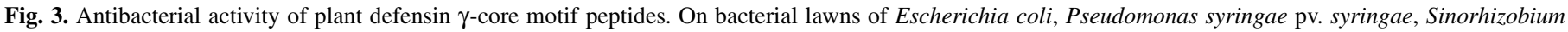

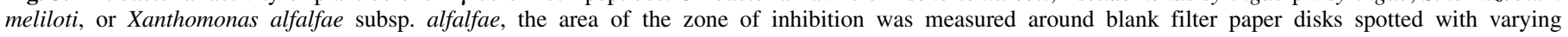

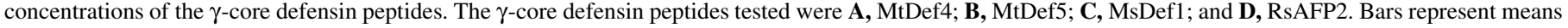
and error bars indicate standard error $(n=9)$. 
TABLE 4. Activity of the $\gamma$-core motif defensin peptides against human bacterial pathogens ${ }^{\mathrm{a}}$

\begin{tabular}{lcccc}
\hline Defensin & $\begin{array}{c}\text { Serratia } \\
\text { marcescens }\end{array}$ & $\begin{array}{c}\text { Enterobacter } \\
\text { aerogenes }\end{array}$ & $\begin{array}{c}\text { Enterococcus } \\
\text { casseliflavus }\end{array}$ & $\begin{array}{c}\text { Pseudomonas } \\
\text { aeruginosa }\end{array}$ \\
\hline Core MtDef4 & $8.4 \pm 1.0$ & $2.3 \pm 0.3$ & NA & $2.7 \pm 0.1$ \\
Core MtDef5 & $6.0 \pm 0.7$ & $2.8 \pm 0.3$ & NA & $11.8 \pm 1.4$ \\
\hline
\end{tabular}

a The mean amount of defensin needed to inhibit growth of the bacterial pathogens strains by $50 \%(\mu \mathrm{M})$ values are reported \pm standard error of three independent experiments $(n=3)$. NA indicates that the defensins at a concentration of $30 \mu \mathrm{g} / \mathrm{ml}$ showed no biological activity against the pathogens.

amounts of defensin peptides but these peptides have low biological activity due to problematic structural integrity (Lacerda et al. 2014). We have shown that truncated defensin peptides containing the $\gamma$-core motif can be chemically synthesized and may mimic the relative antimicrobial activity of the full-length defensins (Tables 2 and 3). This warrants the further investigation of the predictive capabilities of $\gamma$-core motif defensin peptides from species other than $M$. truncatula. In combination with the described microplate and spread-plate methods, $\gamma$-core motif peptides could be used to quickly screen defensins for antimicrobial activity, which would greatly simplify and expedite defensin bioassays.

In this report, we characterized the in vitro antifungal and antibacterial activity of plant defensins against alfalfa crown rot pathogens and human bacterial pathogens. Full-length defensins were shown to have antimicrobial activity against both fungal and bacterial pathogens at nanomolar concentrations. These experiments show the previously overlooked high biological activity of plant defensins against bacterial pathogens. Additionally, these results indicate that the $\gamma$-core motif peptide may be used to predict the relative biological activity of the full-length defensin. Specifically, MtDef4 and MtDef5 were identified as ideal candidates for transgenic expression in alfalfa due to their broad-spectrum and strong antimicrobial activity. Transgenic expression of these defensins could be utilized to implement an ecofriendly, proteinbased strategy that could provide alfalfa with enhanced resistance against crown rot and growers with reciprocal gains in yield.

\section{ACKNOWLEDGMENTS}

We thank D. Foster-Hartnett, University of Minnesota, for providing the American Type Culture Collection bacterial cultures. This article is a joint contribution from the Plant Science Research Unit, United States Department of Agriculture (USDA) Agricultural Research Service, and the Minnesota Agricultural Experiment Station. USDA is an equal opportunity provider and employer. Mention of any trade names or commercial products in this article is solely for the purpose of providing specific information and does not imply recommendation or endorsement by the U. S. Department of Agriculture.

\section{LITERATURE CITED}

Abdallah, N. A., Shah, D., Abbas, D., and Madkour, M. 2010. Stable integration and expression of a plant defensin in tomato confers resistance to Fusarium wilt. GM Crops 1:344-350.

Aerts, A. M., François, I. E. J. A., Cammue, B. P. A., and Thevissen, K. 2008. The mode of antifungal action of plant, insect and human defensins. Cell. Mol. Life Sci. 65:2069-2079.

Balandín, M., Royo, J., Gómez, E., Muniz, L. M., Molina, A., and Hueros, G. 2005. A protective role for the embryo surrounding region of the maize endosperm, as evidenced by the characterization of ZmESR-6, a defensin gene specifically expressed in this region. Plant Mol. Biol. 58:269-282.

Broekaert, W. F., Terras, F. R. G., Cammue, B., and Vanderleyden, J. 1990. An automated quantitative assay for fungal growth inhibition. FEMS Microbiol. Lett. 69:55-59.

Carvalho, A. de O., and Gomes, V. M. 2009. Plant defensins-prospects for the biological functions and biotechnological properties. Peptides 30:1007-1020.

Cools, T., Struyfs, C., Cammue, B., and Thevissen, K. 2017. Antifungal plant defensins: Increased insight in their mode of action as a basis for their use to combat fungal infections. Future Microbiol. 12:441-454.
De Coninck, B., Cammue, B. P. A., and Thevissen, K. 2013. Modes of antifungal action and in planta functions of plant defensins and defensin-like peptides. Fungal Biol. Rev. 26:109-120.

Dias, R. D. O., and Franco, O. L. 2015. Cysteine-stabilized $\alpha \beta$ defensins: From a common fold to antibacterial activity. Peptides 72:64-72.

Francisco, G. C., and Georgina, E. 2017. Structural motifs in class I and class II plant defensins for phospholipid interactions: Intriguing role of ligand binding and modes of action. J. Plant Physiol. Pathol. 5:1.

Franco, O. L., Murad, A. M., Leite, J. R., Mendes, P. A. M., Prates, M. V., and Bloch, C. 2006. Identification of a cowpea $\gamma$-thionin with bactericidal activity. FEBS J. 273:3489-3497.

Fujimura, M., Minami, Y., Watanabe, K., and Tadera, K. 2003. Purification, characterization, and sequencing of a novel type of antimicrobial peptides, Fa-AMP1 and Fa-AMP2, from seeds of buckwheat (Fagopyrum esculentum Moench.). Biosci. Biotechnol. Biochem. 67:1636-1642.

Gao, A. G., Hakimi, S. M., Mittanck, C. A., Wu, Y., Woerner, B. M., Stark, D. M., Shah, D. M., Liang, J., and Rommens, C. M. T. 2000. Fungal pathogen protection in potato by expression of a plant defensin peptide. Nat. Biotechnol. 18:1307-1310.

Guillén-Chable, F., Arenas-Sosa, I., Islas-Flores, I., Corzo, G., Martinez-Liu, C., and Estrada, G. 2017. Antibacterial activity and phospholipid recognition of the recombinant defensin J1-1 from Capsicum genus. Protein Expr. Purif. 136:45-51.

Islam, K. T., Velivelli, S. L. S., Berg, R. H., Oakley, B., and Shah, D. M. 2017. A novel bi-domain plant defensin MtDef5 with potent broad-spectrum antifungal activity binds to multiple phospholipids and forms oligomers. Sci. Rep. 7: Article 16157.

Kaur, J., Thokala, M., Robert-Seilaniantz, A., Zhao, P., Peyret, H., Berg, H., Pandey, S., Jones, J., and Shah, D. 2012. Subcellular targeting of an evolutionarily conserved plant defensin MtDef4.2 determines the outcome of plant-pathogen interaction in transgenic Arabidopsis. Mol. Plant Pathol. 13: 1032-1046.

Lacerda, A. F., Vasconcelos, É. A. R., Pelegrini, P. B., and Grossi de Sa, M. F. 2014. Antifungal defensins and their role in plant defense. Front. Microbiol. 5:1-10.

Lay, F., and Anderson, M. 2005. Defensins-Components of the innate immune system in plants. Curr. Protein Pept. Sci. 6:85-101.

Leath, K. T., Erwin, D. C., and Griffin, G. D. 1988. Diseases and nematodes. Pages 621-670 in: Alfalfa and Alfalfa Improvement. A. A. Hanson, D. K. Barnes, and R. R. Hill, Jr., eds. American Society of Agronomy, Crop Science Society of America, and Soil Science Society of America, Madison, WI.

Lobo, D. S., Pereira, I. B., Fragel-Madeira, L., Medeiros, L. N., Cabral, L. M., Faria, J., Bellio, M., Campos, R. C., Linden, R., and Kurtenbach, E. 2007. Antifungal Pisum sativum defensin 1 interacts with Neurospora crassa cyclin F related to the cell cycle. Biochemistry 46:987-996.

Miller-Garvin, J. E., and Viands, D. R. 1994. Selection for resistance to Fusarium root rot, and associations among resistance to six diseases of alfalfa. Crop Sci. 34:1461-1465.

Muñoz, A., Chu, M., Marris, P. I., Sagaram, U. S., Kaur, J., Shah, D. M., and Read, N. D. 2014. Specific domains of plant defensins differentially disrupt colony initiation, cell fusion and calcium homeostasis in Neurospora crassa. Mol. Microbiol. 92:1357-1374.

Osborn, R. W., De Samblanx, G. W., Thevissen, K., Goderis, I., Torrekens, S., Van Leuven, F., Attenborough, S., Rees, S. B., and Broekaert, W. F. 1995. Isolation and characterization of plant defensins from seeds of Asteraceae, Fabaceae, Hippocastanaceae and Saxifragaceae. FEBS Lett. 368:257-262.

Parisi, K., Shafee, T. M. A., Quimbar, P., van der Weerden, N. L., Bleackley, M. R., and Anderson, M. A. The evolution, function and mechanisms of action for plant defensins. Semin. Cell Dev. Biol. In press. doi:10.1016/j. semcdb.2018.02.004

Sagaram, U. S., El-Mounadi, K., Buchko, G. W., Berg, H. R., Kaur, J., Pandurangi, R. S., Smith, T. J., and Shah, D. M. 2013. Structural and functional studies of a phosphatidic acid-binding antifungal plant defensin MtDef4: Identification of an RGFRRR motif governing fungal cell entry. PLoS One 8:e82485.

Sagaram, U. S., Pandurangi, R., Kaur, J., Smith, T. J., and Shah, D. M. 2011. Structure-activity determinants in antifungal plant defensins MsDef1 and MtDef4 with different modes of action against Fusarium graminearum. PLoS One 6:e18550.

Segura, A., Moreno, M., Molina, A., and García-Olmedo, F. 1998. Novel defensin subfamily from spinach (Spinacia oleracea). FEBS Lett. 435: 159-162.

Sharma, K. K., Pothana, A., Prasad, K., Shah, D., Kaur, J., Bhatnagar, D., Chen, Z. Y., Raruang, Y., Cary, J. W., Rajasekaran, K., Sudini, H. K., and Bhatnagar-Mathur, P. 2017. Peanuts that keep aflatoxin at bay: A threshold that matters. Plant Biotechnol. J. 16:1024-1033.

Spelbrink, R. G., Dilmac, N., Allen, A., Smith, T. J., Shah, D. M., and Hockerman, G. H. 2004. Differential antifungal and calcium channel- 
blocking activity among structurally related plant defensins. Plant Physiol. 135:2055-2067.

Stover, E. D., Stange, R. R., McCollum, T. G., Jaynes, J., Irey, M., and Mirkov, E. 2013. Screening antimicrobial peptides in vitro for use in developing transgenic citrus resistant to Huanglongbing and Citrus canker. J. Am. Soc. Hortic. Sci. 138:142-148.

Terras, F., Schoofs, H., De Bolle, M., Van Leuven, F., Rees, S., Vanderleyden, J., Cammue, B. P., and Broekaert, W. F. 1992. Analysis of two novel classes of plant antifungal proteins from radish (Raphanus sativus L.). J. Biol. Chem. 267:15301-15309.

Thevissen, K., Cammue, B. P. A., Lemaire, K., Winderickx, J., Dickson, R. C., Lester, R. L., Ferket, K. K., Van Even, F., Parret, A. H., and Broekaert, W. F. 2000. A gene encoding a sphingolipid biosynthesis enzyme determines the sensitivity of Saccharomyces cerevisiae to an antifungal plant defensin from dahlia (Dahlia merckii). Proc. Natl. Acad. Sci. USA 97:9531-9536.

Thevissen, K., Francois, I. E. J. A., Aerts, A. M., and Cammue, B. P. A. 2005. Fungal sphingolipids as targets for the development of selective antifungal therapeutics. Curr. Drug Targets 6:923-928.

Thevissen, K., Ghazi, A., De Samblanx, W., Brownlee, C., Osborn, R. W., and Broekaert, W. F. 1996. Fungal membrane responses induced by fungal membrane responses induced by plant defensins and thionins. J. Biol. Chem. 271:15018-15025.

Thevissen, K., Kristensen, H. H., Thomma, B. P. H. J., Cammue, B. P. A., and François, I. E. J. A. 2007. Therapeutic potential of antifungal plant and insect defensins. Drug Discov. Today 12:966-971.

Thevissen, K., Osborn, R. W., Acland, D. P., and Broekaert, W. F. 1997. Specific, high affinity binding sites for an antifungal plant defensin on Neurospora crassa hyphae and microsomal membranes. J. Biol. Chem. 272:32176-32181.
Thevissen, K., Terras, F. R. G., and Broekaert, W. F. 1999. Permeabilization of fungal membranes by plant defensins inhibits fungal growth. Appl. Environ. Microbiol. 65:5451-5458.

Thevissen, K., Warnecke, D. C., Francois, I. E. J. A., Leipelt, M., Heinz, E., Ott, C., Zahringer, U., Ferket, K. K., and Cammue, B. P. 2004. Defensins from insects and plants interact with fungal glucosylceramides. J. Biol. Chem. 279:3900-3905.

Thomma, B. P. H. J., Cammue, B. P. A., and Thevissen, K. 2002. Plant defensins. Planta 216:193-202.

Turner, V., and Van Alfen, N. K. 1983. Crown rot of alfalfa in Utah. Phytopathology 73:1333-1337.

Uddin, W., and Knous, T. R. 1991. Fusarium species associated with crown rot of alfalfa in Nevada. Plant Dis. 75:51-56.

van der Weerden, N. L., and Anderson, M. A. 2013. Plant defensins: Common fold, multiple functions. Fungal Biol. Rev. 26:121-131.

Velivelli, S. L. S., Islam, K. T., Hobson, E., and Shah, D. M. 2018. Modes of action of a bi-domain plant defensin MtDef5 against a bacterial pathogen Xanthomonas campestris. Front. Microbiol. 9:934.

Vriens, K., Cammue, B. P. A., and Thevissen, K. 2014. Antifungal plant defensins: Mechanisms of action and production. Molecules 19:1228012303.

Wilcoxson, R. D., Barnes, D. K., Frosheiser, F. I., and Smith, D. M. 1977. Evaluating and selecting alfalfa for reaction to crown rot. Crop Sci. 17: 93-96.

Yount, N. Y., and Yeaman, M. R. 2004. Multidimensional signatures in antimicrobial peptides. Proc. Natl. Acad. Sci. USA 101:7363-7368.

Zhang, Y., and Lewis, K. 1997. Fabatins: New antimicrobial plant peptides. FEMS Microbiol. Lett. 149:59-64. 